\title{
México y las cruzadas anticomunistas estadunidenses, 1924-1964
}

Jürgen Buchenau

UNIVERSITY OF NORTH CAROLINA AT CHARLOTTE

\begin{abstract}
Este trabajo analiza la reacción mexicana ante las cruzadas anticomunistas de Estados Unidos durante tres episodios:

la presidencia de Calles, la Guatemala de Arbenz, y el gobierno revolucionario de la Cuba de Castro. El tema permite analizar la intrigante paradoja de que, durante la guerra fría, un régimen anticomunista -producto de una revolución que el gobierno estadunidense calificó alguna vez de bolchevique- practicara una política amistosa hacia movimientos supuestamente comunistas.
\end{abstract}

$\mathrm{E}$ ntre 1917 y 1990, Estados Unidos emprendió una serie de cruzadas anticomunistas en Latinoamérica, que combinaron los dos temores llamados nacionalismo y revolución social en el área. ${ }^{1}$ Los "Guerreros de la guerra fría" que ayudaron a definir la política exterior de Estados Unidos desde el comienzo de la revolución bolchevique, tacharon a cualquier comunista latinoamericano que fuera partidario de reformas sociales

\footnotetext{
'Para un análisis excelente de los temores estadunidenses ante las revoluciones sociales, ver Hunt, Ideology, 1987.
}

de ser inaceptable para Estados Unidos. ${ }^{2}$ A lo largo de este periodo, los supuestos comunistas han sido persona. jes tan disparejos como Plutarco Elias Calles, de México, o Juan Domingo Perón, de Argentina, así como comunistas "verdaderos" como Fidel Castro, de Cuba. Esta actitud de los arquitectos de la política exterior se intensificó al convertirse la Unión Soviética en una potencia mundial, y usaron el espectro del

\footnotetext{
${ }^{2}$ La tesis implícita de que las cruzadas anticomunistas datan de la revolución bolchevique en vez de la guerra fría sigue a Leffler, Specter, 1994.
} 
comunismo para justificar la intervención militar estadunidense en Latinoamérica, la más reciente, durante la crisis centroamericana de los ochenta.

Estas cruzadas anticomunistas han sido bien investigadas por los estudiosos de las relaciones exteriores de Estados Unidos y se basan, ante todo, en los archivos estadunidenses. La mayoría de los estudios se dividen en tres categorías: los "realistas", que alegan que las percepciones estratégicas impulsan a la política; los "revisionistas", que enfatizan la importancia de los grupos de presión económicos; y finalmente los "pluralistas", que ven una serie de motivaciones conectadas entre sí. ${ }^{3}$ Salvo pocas excepciones, pues, el estudio de este tema ha sido dominado por los historiadores que ven al Estado como un actor racional y unitario. Esta

preferencia para resumir patrones de actividad referente a la política exterior [...] más que disertar acerca de ella, tiene su origen en la tendencia común prevaleciente entre los estudiosos de las relaciones internacionales modernas, de que las acciones hablan con más fuerza que las palabras. ${ }^{4}$

Lo que es aún más importante, las investigaciones acerca de la política exterior estadunidense exceden por mucho a aquellas que ponen a los latinoamericanos en el centro de la investigación histórica, sin contar las que em-

\footnotetext{
${ }^{3}$ Para un representante del "realismo", véase a Leonard, Central, 1989. Para una perspectiva "revisionista", ver a LaFeber, Inevitable, 1993. Arnson, Crossroads, 1995, usa el marco "pluralista."

${ }^{4}$ Coatsworth, Central, 1994, p. IX.
}

prenden el arduo camino de extraer la información de los archivos en Latinoamérica así como en Estados Unidos.

Las respuestas latinoamericanas a la cruzada anticomunista están lejos de ser entendidas. Las investigaciones acerca del impacto de esta cruzada sobre la política exterior de las naciones latinoamericanas, $y$, ante todo, sobre aquellas que practicaron una política doméstica anticomunista, nos permiten discernir la manera como las naciones latinoamericanas crean su política exterior. En lo particular, el caso de México nos da una gran oportunidad de analizar esta intrigante paradoja, ya que su régimen anticomunista -el producto de una revolución que el gobierno estadunidense alguna vez calificó de bolchevique- practicó una política exterior amistosa hacia movimientos supuestamente comunistas durante la guerra fría. En primer lugar, este ejemplo tiene mucho que enseñarnos acerca de la manera en que se maneja la política exterior, ya que el término "comunismo" nunca tuvo el mismo significado en México que en Estados Unidos. Por el otro lado, las reacciones mexicanas hacia el anticomunismo estadunidense nos permiten discernir cómo los latinoamericanos han podido ser capaces de resistir el dominio de Estados Unidos.

Este trabajo de investigación analiza las cruzadas anticomunistas de Estados Unidos y la manera como reaccionaron los mexicanos ante ellas durante tres episodios: el temor rojo en México, durante la presidencia de Plutarco Elías Calles (1926-1927); la intervención estadunidense en la Guatemala de Jacobo Arbenz (1951-1954) y, final- 
mente, la política de Estados Unidos hacia el gobierno revolucionario cubano de Fidel Castro (1959-1964). Un episodio final, y quizá el más interesante -la guerra no declarada de Ronald Reagan en contra del gobierno sandinista de Nicaragua (1981-1990)-, ya ha sido extensamente estudiado por otros. ${ }^{5}$

\section{ESTADOS UNIDOS CONTRA "MÉxICO ROJO," 1924-1927}

Durante las dos primeras décadas del siglo $\mathrm{XX}$, Estados Unidos se preocupó más por las inversiones y rutas comerciales que por los comunistas en Latinoamérica. La política exterior estadunidense buscó la estabilidad política en América Latina, tanto como un fin en sí mismo y como la condición más importante para la expansión económica. Los países que bordeaban el Caribe fueron vistos como el "perímetro estratégico" del país, y la mayoría de las inversiones estadunidenses en Latinoamérica se concentraban allí. Estas inversiones produjeron una economia distorsionada, debido a que se concentraban en los ferrocarriles y en los artículos de consumo tropicales. ${ }^{6}$ Al mismo tiempo, Estados Unidos in.

\footnotetext{
5 Ojeda, Relaciones, 1985; Best, "Mexican", 1988; Bagley, "Mexico", 1984, pp. 261-284; Bagley, "Mexican", 1983, pp. 406-409, 437; Grabendorff, "Role", 1984, pp. 83-100; Herrera, "Política", 1983, pp. 423-440; Pellicer, "México", 1972; Ojeda, "Mexican", 1983, y Aguilar Zinser, "México", 1983, pp. 119-133, 135-160, y 161-186.

${ }^{6}$ Para dos estudios recientes de los empresarios bananeros, véase a Dosal, Doing, 1993; y Langley, Banana, 1995.
}

crementó su presencia militar y le hizo saber al mundo que resistiría cualquier interferencia externa. Debido a que el gobierno estadunidense creía que cualquier disturbio de índole político amenazaba directamente los intereses vitales de la nación, intervino militarmente en Cuba, en la República Dominicana, Haití, México y Nicaragua. Aun después de que la primera guerra mundial había dejado a Estados Unidos como la única potencia dominante en el continente, el gobierno estadunidense siguió atemorizado por la inestabilidad. Aunque algunas de estas intervenciones tuvieran a los movimientos nacionalistas como objetivo principal, las ideologías hostiles no figuraban entre las razones para ordenar una acción militar.

Las dos grandes revoluciones al inicio del siglo $\mathrm{xx}$-la mexicana y la bolchevique- ${ }^{7}$ no cambiaron al principio el enfoque estadunidense hacia Latinoamérica. La revolución mexicana, fundamentalmente agraria y política, nunca desarrolló una ideología definida $\mathrm{y}$, a pesar del énfasis nacionalista de la Constitución de 1917, mantuvo su carácter capitalista. ${ }^{8}$ Por el otro lado, la lejana Unión Soviética inicialmente estuvo demasiado ocupada luchando en contra de los levantamientos contrarrevolucionarios para dedicarse a la exportación de su revolución. A pesar de ello, el embajador estadunidense en México, Henry P. Fletcher, pintó un vivo cuadro de la colaboración mexicano-soviética, que fomentaba los le-

${ }^{7}$ Spenser, Triángulo, 1998, estudia las dos revoluciones dentro del contexto de la política internacional de Estados Unidos.

${ }^{8}$ Knight, Mexican, 1986. 
vantamientos de las clases populares empobrecidas en Latinoamérica. Además, él invocó la inocua Doctrina Carranza (una declaración hecha por el presidente Venustiano Carranza, que alentaba a las naciones latinoamericanas a defender su derecho a la autodeterminación) como una prueba de que México deseaba exportar su revolución. ${ }^{9}$ Hacia 1920 , sin embargo, al acallar la destrucción generalizada y el conflicto faccional, tanto a los socialistas idealistas como a los agraristas, los arquitectos de la política exterior estadunidense se percataron de que la revolución mexicana carecía de la dirección y el enfoque ideológico de los líderes soviéticos. Mientras que el gobierno estadunidense esperó tres años para otorgar el reconocimiento diplomático al nuevo presidente, Álvaro Obregón, y así prevenir una expropiación de los bienes extranjeros al estilo soviético, no vio a agentes soviéticos operando en México. ${ }^{10}$ De hecho, las elites latinoamericanas se preocupaban mucho más por la revolución mexicana que sus contrapartes en Estados Unidos. Cuando rebeldes guatemaltecos y salvadoreños invocaron los nombres de los líderes revolucionarios Emiliano Zapata y Pancho Villa, los líderes centroamericanos culparon a los agitadores mexicanos de los disturbios. ${ }^{11}$ Los documentos históricos, sin embargo,

\footnotetext{
${ }^{9}$ Fletcher al secretario, México, 3 de julio de 1918 en National Archives of Washington (en adelante NAW), Estados Unidos, Record Group 59: Records of the Department of State, $711.12 / 116$ y anexo.

${ }^{10}$ Krenn, U.S., 1990, pp. 143-44.

${ }^{11}$ Buchenau, Sbadow, 1996, p. 146.
}

prueban que el pragmático Obregón había decepcionado hasta a sus propios diplomáticos en Latinoamérica, al negarles el apoyo a los movimientos que pedían un cambio social. ${ }^{12}$ Un periodista estadunidense escribiría, unos años más tarde: "México marcha con música, estandartes y flores. Nosotros marchamos con ametralladoras, dólares y marines." ${ }^{13}$ No fue sino hasta 1924 cuando los esfuerzos reformistas del presidente Calles -que coincidieron con el establecimiento de las relaciones diplomáticas con la Unión Soviéticaprovocaron el surgimiento de acusaciones estadunidenses sobre la existencia del bolchevismo en México.

Durante sus primeros dos años en la presidencia, Calles movió a la revolución mexicana hacia la izquierda, y tenía bastantes razones para hacerlo. Ante todo, el nuevo presidente asumió su cargo un tanto débilitado en lo que a estatura política se refiere. A diferencia de Obregón (que fue un auténtico héroe), Calles no había tenido hasta entonces victorias militares ni logros políticos. Es más, le debía su cargo al apoyo de su mentor. Para lograr escapar de la sombra de su predecesor (un esfuerzo que no fue exitoso del todo sino hasta el asesinato de Obregón en 1928), Calles empezó a cultivar la amistad de aquellos líderes que no tenían relaciones personales íntimas con su antecesor. Mientras que la gran mayoría de los líderes militares daban todo

\footnotetext{
12 Ruiz a Obregón, Managua, 7 de marzo de 1923, Boletín del Arcbivo General de la Nación, vol. 11, 1980, México, p. 5.

13 Beals, "Mexico", 1926, p. 840.
} 
su apoyo a Obregón, él se unió a la suerte de Luis $\mathbf{N}$. Morones, el jefe de la moderada Confederación Regional Obrera Mexicana (CROM). Como agradecimiento al apoyo de Morones, $\mathrm{Ca}$ lles le ayudó a la CROM a subyugar a los otros sindicatos más radicales, llevándola así al dominio nacional. Con Morones, como secretario del Trabajo, éste se encontraba en el mejor lugar para incrementar el poder del Estado revolucionario mediante la creación de alianzas con las organizaciones populares. Hacia principios de 1925, Calles se había autoproclamado el paladín del movimiento trabajador urbano, y comenzó a poner en vigor las cláusulas nacionalistas y anticlericales de la Constitución de $1917 .^{14}$

Impulsado por Morones, Calles empezó a cerrar algunos huecos de la Constitución que habían quedado pendientes. Poco después de llegar al poder, firmó una serie de decretos que hicieron respetar sus cláusulas anticlericales, y también se rehusó a respaldar los Convenios de Bucareli. En 1925, cuando la producción petrolífera ya había caído en picada por cuatro años, Calles volvió su mirada a la poderosa industria del petróleo. Acusando a los petroleros de recortar a propósito la producción para forzar a su gobierno a revocar el artículo 27 constitucional, rápidamente logró que el Congreso aprobara una nueva ley petrolífera. Esta nueva ley requería que las compañias petrolíferas extranjeras que operaban en México solicitaran permiso para confirmar sus concesiones y, de

${ }^{14}$ Meyer, México, 1972, p. 107. no hacerlo, podrían ser nacionalizadas. Este paso, más la campaña de Calles para eliminar a la jerarquía católica, ayudó a movilizar un fuerte movimiento opositor que surgió de una diversa coalición estadunidense que incluía a los inversionistas, a los católicos y al secretario de Estado, Frank B. Kellogg, quien declaró, en 1925, que México "estaba sujeto a juicio ante el mundo". ${ }^{15}$

Las iniciativas de Calles estuvieron guiadas por un pragmatismo más que por un compromiso idealista hacia la revolución mexicana, para no mencionar las ideas bolcheviques. Aun cuando sus medidas hicieran que poderosos sectores de la economía mexicana le retiraran su apoyo, reivindicaron la herencia revolucionaria con la meta de crear un Estado fuerte y centralizado. Significativamente, las reformas estuvieron enfocadas hacia aquellos grupos que impedían la creación de tal Estado: el clero, los petroleros y los latifundistas. Convencido de que lo mejor para el país era una economía capitalista que le perteneciera a los mexicanos, Calles no deseaba hundir el barco. Al igual que Obregón, tenía la visión de impulsar y dirigir la revolución por un camino ordenado y controlado por el gobierno. Como nos indican los giros que más tarde le dio a sus reformas (por cierto bien documentados), Calles, al igual que su predecesor, se dio cuenta de que los principios políticos eran de suma conveniencia. Firmemente anticomunista, consideraba cualquier reforma como una manera de

${ }^{15}$ Ibid, pp. 107-114. 
adelantarse a las demandas de un cambio más radical. ${ }^{16}$

Por lo tanto, el apelativo de comunista/bolchevique entró al vocabulario estadunidense como una arma política que se podía usar en contra de Calles, más que como una descripción de su política. No sorprende, pues, que los "Knights of Columbus" (Caballeros de Colón) o la prensa amarillista de William R. Hearst (en otras palabras, el catolicismo organizado y la prensa amarillista de derecha) fueran unos de los primeros en usar este apelativo. Sin embargo, no encontraron un gran apoyo entre los responsables de la política exterior estadunidense hasta que el embajador, James R. Sheffield, quien estaba íntimamente involucrado con los intereses petrolíferos, determinó que la palabra bolchevique en efecto describía al gobierno de Calles. El miope Sheffield, quien consideraba a los mexicanos primitivos y atrasados, ${ }^{17}$ exageró las actividades de unas cuantas pequeñas organizaciones marxistas para demostrar que México se estaba "sovietizando". Asimismo, tachó al anticomunista Morones de "bolchevique" y se convenció de que la legación soviéti-

\footnotetext{
${ }^{16}$ Hasta que se publique el muy anticipado libro de Carlos Macías, no habrá una buena biografia de Calles que trata de su gestión presidencial. Para el análisis más amplio de su gestión, véase Meyer, Historia, 1977.

${ }^{17}$ Por ejemplo, Sheffield declaró que "Estados Unidos [...] con su civilización bien ordenada $[\ldots]$ tiene el deber de prestarle a México $[\ldots]$ toda la ayuda para mejorar $[\ldots]$ este pueblo tan retrasado." Sheffield a Wadsworth, México, 4 de marzo de 1924, en Yale University Library, James $R$. Sbeffield Papers, Series I, caja 5, exp. 49.
}

ca se encontraba detrás del supuesto cambio de dirección hacia el bolchevismo. ${ }^{18}$

Aunque Kellogg no compartía la paranoia de Sheffield, pronto se dio cuenta de que le convenía tachar a México de comunista, ya que le servía para sus propios propósitos de política exterior. Kellogg y sus ayudantes no le dieron demasiado crédito a los comunicados de Sheffield, e incluso el Departamento de Estado admitió en un memorándum que "hay poca evidencia concreta [...] que el gobierno mexicano en sí es un gobierno bolchevista". De hecho, proseguia el memorándum "la palabra 'bolchevista' se ha convertido más en un epíteto que en una definición útil". ${ }^{19}$ Pero los informes de Sheffield le ayudaron mucho a Kellogg para poder justificar una política de mano dura hacia México. A sabiendas de que una analogía entre México y la Unión Soviética podría provocar que la opinión pública estadunidense se volcara en contra de los esfuerzos de Calles por reglamentar la industria del petróleo, Kellogg filtró los comunicados de Sheffield a la prensa de Hearst, oportunamente.

Cuando en el otoño de 1926 Calles empezó a darle su apoyo militar a la rebelión liberal nicaragüense, de corte moderadamente nacionalista bajo el liderazgo de Juan B. Sacasa, dio a Kellogg una razón más para acusar a Mé-

\footnotetext{
${ }^{18}$ Horn, "Embajador", 1970, pp. 265-284; y Horn, "U.S.", 1975, pp. 32-33.

19 "Confidential Memorandum", sin firma, iniciales REO [posiblemente Robert E. Olds o Arthur B. Lane para Olds], 1926 (sin fecha) en Yale University Library, Arthur Bliss Lane Papers, caja 56a, folder 986.
} 


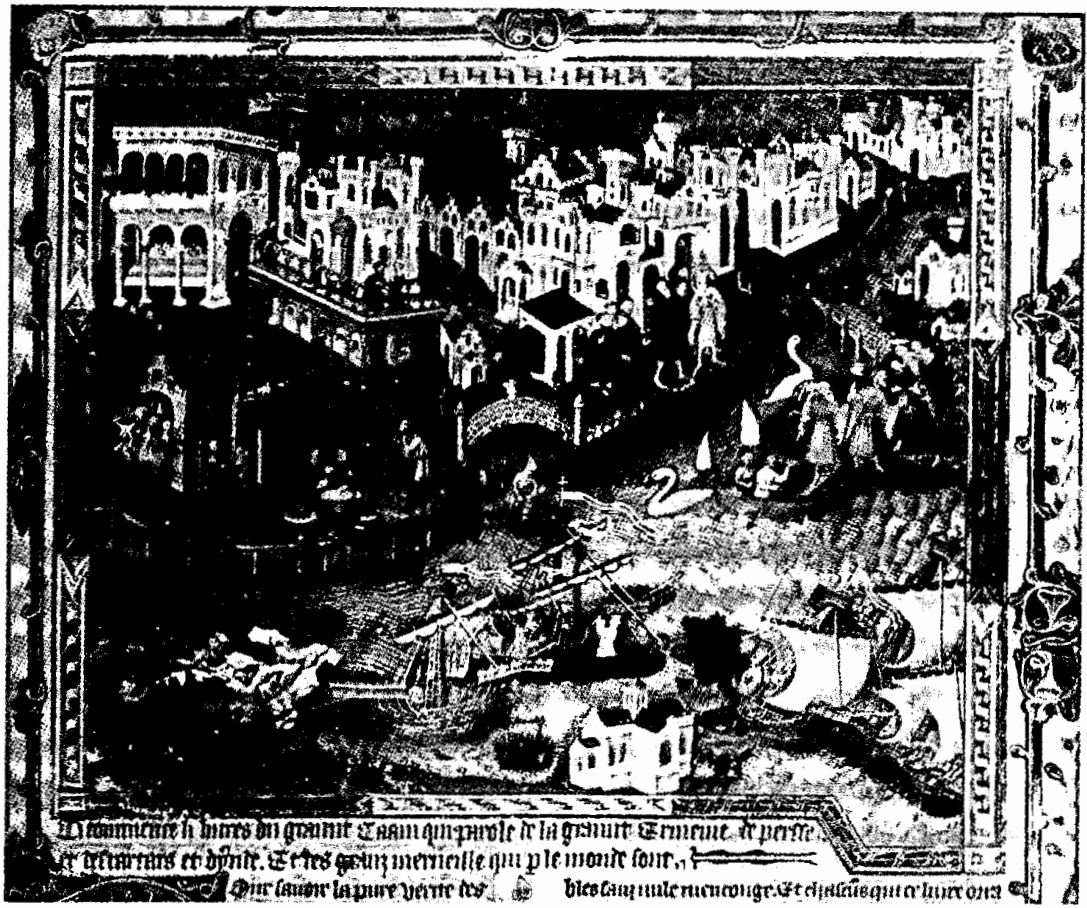

xico de ser bolchevique. ${ }^{20}$ Mientras que el bolchevismo mexicano no era una quimera suficientemente diseñada para ejercer presión sobre el gobierno mexicano, la idea de que el comunismo amenazaba a Centroamérica rayaba en lo ridículo. Sacasa era un político aburrido de clase media, que estaba más interesado en su trayectoria política que en ideas progresistas, por no decir

${ }^{20}$ Para esta ayuda militar véase Buchenau, México, y Buchenau, Shadow, 1996, cap. 7. nada de ideas socialistas o comunistas. ${ }^{21}$ Antes de acercarse al embajador mexicano en Washington, él había buscado en el Departamento de Estado el apoyo para su rebelión, y el embajador le había aconsejado a Calles que, por esa razón, no le prestara su apoyo al nicaragüense. ${ }^{22}$ Desgraciadamente, $\mathrm{Ca}$ -

${ }^{21}$ Selser, "Pequeño", 1980, p. 18.

${ }^{22}$ Manuel Téllez a SRE, Washington, 16 de febrero y 17 de marzo de 1926, en Archivo Histórico de la Secretaría de Relaciones Exteriores 
lles tuvo el infortunio de que Chandler P. Anderson, la persona que presionaba por los intereses del opositor de Sacasa, Emiliano Chamorro, era también el representante de las compañías petrolíferas estadunidenses en Washington. Dados los comunicados de Sheffield y el interés de Kellogg en refrenar a México, tanto en el frente petrolífero como en el nicaragüense, el razonamiento de Anderson de que el bolchevismo internacional se había infiltrado tanto en México como en Nicaragua era precisamente lo que el Departamento de Estado quería oír. ${ }^{23}$

Dentro de este contexto, Sheffield declaró ante el Comité de Relaciones Exteriores del Senado, el 12 de enero de 1927. Herido por la crítica de senadores estadunidenses tales como William Borah y Burton Wheeler hacia su política latinoamericana, el presidente Coolidge ya había hablado en contra de una intervención mexicana en un mensaje dado al Congreso dos días antes, aunque sin mencionar las palabras "comunista" ni "bolchevique." reunión con el Comité de Relaciones Exteriores del Senado, Kellogg acusó al gobierno de Calles de extender el bolchevismo en Latinoamérica y anunció que el gobierno estadunidense no toleraría tal exportación de ideologías radicales. ${ }^{25}$ Después de la reunión con el

de México (en adelante AHSREM), 20-2-15 (I), pp. 146-149 y 165-166.

${ }^{23}$ Harrison, Dollar, 1988.

${ }^{24}$ Coolidge, Conditions, 1927.

${ }^{25}$ Kellogg, "Bolshevik Aims and Policies in Mexico and Latin America", Library of Congress, Manuscript Division (en adelante LCMSs), Frank B. Kellogg Papers (microfilme), rollo 24, marcos 141.159.
Senado, los editoriales de los diarios estadunidenses y mexicanos mencionaron la posibilidad de una guerra entre las dos naciones. ${ }^{26}$ Sin embargo, y a pesar de una retórica tan acalorada, una intervención estadunidense nunca estuvo cercana. ${ }^{27}$ Lejos de pensar que México era bolchevique, él había intentado obtener el apoyo para sus campanas simultáneas, para poder imponer $s u$ manera de pensar en Centroamérica y así parar en seco el nacionalismo económico mexicano.

La propaganda estadunidense en contra de México fue escuchada con sumo interés por los centroamericanos, quienes astutamente se aprovecharon de esta oportunidad para acaparar la atención de Kellogg. Fl adversario de Sacasa, Adolfo Díaz, culpó al bolchevismo mexicano de la rebelión. ${ }^{28}$ El gobierno salvadoreño cooperó abiertamente con Estados Unidos, y detuvo a una embarcación mexicana que llevaba armas. La vecina Honduras apoyó a Díaz. Finalmente, en el caso de Costa Rica, vemos que una nación centroamericana usó el espectro del comunismo para beneficio propio. A principios de 1927, el presidente Ricardo Jiménez le pidió a Kellogg que actuara en contra del bolchevismo mexicano, ya que de-

\footnotetext{
${ }^{26}$ New York Times, 13 de enero de 1927; Excélsior, 15 de enero de 1927.

${ }^{27}$ Horn, "Did", 1973, pp. 454-471. Segûn Horn, Calles y su gabinete temían esa posibilidad.

${ }^{28}$ Dennis al secretario de Estado, Managua, 8 de diciembre de 1926 , en NAw, Record of the Department of State, 817.00/4197; "Statement of President Diaz", Managua, 2 de enero de 1927, en LCMss, Cbandler P. Anderson Papers, caja 53, exp. 4 .
} 
seaba el apoyo estadunidense para aplastar la rebelión de Jorge Volio, la cual (pese a las declaraciones de Jiménez) México no apoyaba. ${ }^{29}$ Finalmente, el gobierno guatemalteco fue el único que no le otorgó reconocimiento inmediato a Díaz, el candidato escogido por Kellogg en persona. ${ }^{30}$

Estos acontecimientos, aunados a los últimos ataques de Kellogg, provocaron una respuesta de Calles, en la que hábilmente defendió su estatura política. En un comunicado de prensa, el presidente mexicano defendió con valentía la política seguida por su gobierno. Respondiendo a las acusaciones de bolchevismo, declaró que México "no tenía necesidad de doctrinas tan exóticas". Luego negó que el país le hubiese dado algo más que un reconocimiento diplomático al gobierno provisional de Sacasa, pero sostuvo que México tenía el mismo derecho que Estados Unidos de apoyar a un gobierno amistoso. ${ }^{31}$ El secretario de Relaciones

\footnotetext{
${ }^{29}$ Para la actitud costarricense, véase Salisbury, Anti-Imperialism, 1989, pp. 83. Para la de El Salvador, véase Carter, "Kentucky", 1927, p. 321; Jefferson Caffery al secretario de Estado, San Salvador, 26 de agosto y 24 de septiembre de 1926, en NAW, Record of the Department of State, $817.00 / 3796$ y 3936 ; y correspondencia entre Julio Madero y SRE, en AHSREM, 20-2-15 (I), pp. 194-225.

${ }^{30}$ Excélsior, Guatemala, 3 de diciembre de 1926; Clark Kerr al Foreign Office, Guatemala, 14 de diciembre de 1926, Public Records Office, Kew, England, FO 371/11969, pp. 7-8. Esto ocurrió a pesar de la presión considerable por parte del embajador estadunidense para que Guatemala arrestara la "agitación bolchevique" mexicana. Kamman, Searcb, 1968, p. 74.

${ }^{31}$ Excélsior, 9 de enero de 1927. Una copia de esta declaración y un relato de sus orígenes se encuentran en Arturo M. Elías a Soledad Gon-
}

Exteriores de México, Aarón Sáenz, declaró unos días más tarde que su país no tenía ningún interés de índole económico, político o territorial en Nicaragua. La prensa mexicana aportó su opinión por medio de una lluvia de ataques en contra de la política de Kellogg, y ridiculizó las acusaciones de bolchevismo en México hechas por el secretario de Estado. ${ }^{32}$

Sin embargo, la crisis aún no había terminado. En octubre de 1927, la prensa de Hearst declaró haber descubierto una enorme conspiración internacional que involucraba a la Unión Soviética y a los liberales nicaragüenses. Los documentos apócrifos de la supuesta conspiración "revelaron" el apoyo mexicano a Sacasa. Para ese entonces, sin embargo, la opinión pública estadunidense favorecía firmemente las relaciones pacíficas con México, y el incidente pasó con rápidez. De hecho, los reportajes sensacionalistas de los diarios controlados por Hearst, en vez de perjudicar a Calles, más bien le ayudaron: le dieron a él y a México una oportunidad sin igual de detallar otra vez más los puntos sobresalientes de su política exterior.$^{33}$ Además, las burdas falsificaciones atiborradas de erro-

zález, New York, 14 de enero de 1926, Fideicomisos Archivos Calles-Torreblanca, Archivo Plutarco Elías Calles (en adelante APEC, archivo Elías, Arturo M., 21/54, 45-47. Véase también la entrevista entre Calles y Hubert C. Herring en Sheffield al secretario, México, D. F., 10 de enero de 1927 , en NAW, Record of the Department of State, $711.12 / 869$.

${ }^{32}$ Excélsior, 12, 13, 14, y 15 de enero de 1927; El Universal, 13 y 15 de enero de 1927.

${ }^{33}$ Véanse los recortes de prensa en APEC, fondo Reservado, Asuntos México-Nicaragua. 
res gramaticales y de otros tipos ${ }^{34}$ ayudaron a desacreditar a las fuerzas antiCalles en Estados Unidos, compuestas por una coalición de grupos de intereses especiales que no vacilarían en ningún momento en perjudicar al gobierno mexicano.

Finalmente, tanto el gobierno estadunidense como el gobierno anticomunista de Calles habían encontrado un camino para usar las acusaciones de bolchevismo atestadas en contra del gobierno mexicano para sus propios fines. Kellogg logró lo que tanto anhelaba. Bajo la dirección del nuevo embajador en México, Dwight D. Morrow, Estados Unidos logró un aplazamiento más en la cuestión petrolera. Calles, por otro lado, cultivó sus credenciales nacionalistas durante el incidente, mostrando a los mexicanos que su hábil diplomacia había incrementado la estatura política del país en el escenario político mundial. Al retar a Estados Unidos, tanto en México como en Nicaragua (aun si el reto no había sido duradero), y al ser estigmatizado como un enemigo del secretario de Estado, pudo por fin librarse de la sombra de Obregón y fue capaz de crear su propio nicho dentro de la familia revolucionaria. Como los acontecimientos del periodo 1928-1935 mostrarían más tarde, este nicho sería de gran utilidad para forjar el maximato en México. Además, también sirvió para predecir el comportamiento nacional mexicano en las siguientes dos décadas, cuando gobiernos mexicanos más conservadores encontraron conveniente hace

${ }^{34}$ The Boston Herald, 15 de enero de 1927. resaltar su independencia en cuestiones de política exterior, mientras que Estados Unidos emprendió anticomunistas cacerías de brujas en Centroamérica y el Caribe. La primera de estas cacerías tuvo lugar al término de los diez años del experimento guatemalteco en democracia social.

\section{MÉXICO, ESTADOS UNIDOS Y LOS \\ "DIEZ AÑOS DE PRIMAVERA" \\ EN GUATEMAla, 1944-1954}

Después de que una revuelta estudiantil terminó con el brutal gobierno de Jorge Ubico, en octubre de 1944, el nuevo presidente, Juan José Arévalo, comenzó con los primeros intentos de terminar con muchos siglos de control oligárquico en Centroamérica. El antiguo catedrático fue un admirador del modelo revolucionario mexicano, por lo que impulsó la reforma social burguesa, un modesto programa de redistribución de tierras y democracia política. El programa de Arévalo fue bautizado como un "socialismo espiritual" $\mathrm{y}$, aunque era más retórica que sustancia, a fin de cuentas contenía un compromiso verdadero para hacer de Guatemala un país más equitativo. ${ }^{35}$

Al principio, México apoyó el experimento reformista de su vecino. Al fin, un gobierno de la clase media (la esencia del arreglo corporativista mexicano) había llegado a Guatemala. Aunque Mé-

${ }^{35}$ Gleijeses, Shattered, 1991, p. 29. Hay otros, sin embargo, que sostienen que Arévalo era un idealista genuino que favoreció todas las medidas que Arbenz emprendería más adelante. Véase Immerman, CIA, 1982, p. 48. 
xico no había intervenido en la revuelta estudiantil, su embajador expresó públicamente su "simpatía -y la de [su] gobierno- por el pueblo guatemalteco $y$ el triunfo de la democracia $[\ldots]$ en [ese] país". ${ }^{36}$ Más tarde, el gobierno mexicano dio apoyo económico al nuevo gobierno guatemalteco e intensificó los contactos tecnológicos y de intercambio estudiantil.

Hasta 1951, el gobierno de Harry S. Truman no consideró que Guatemala fuera un blanco del comunismo. Con toda su atención fijada en los acontecimientos que sucedían ende Asia y en Europa, le prestó poca atención a lo que pasaba en Guatemala. Boaz Long, el embajador estadunidense, describió a Arévalo como un "reformador soñador" que difícilmente perjudicaría los intereses económicos y estratégicos de Estados Unidos. ${ }^{37}$ Hacia fines de los cuarenta, el comunismo era visto como una amenaza militar directa, y no como la guerra de guerrillas que más tarde caracterizaría a la guerra de Vietnam. Por ello, el concepto de contención de Truman (definido en 1947) se aplicaba a los actos de agresión evidentes que se originaban en una nación comunista, más que a los actos subversivos. ${ }^{38}$ Todavía en 1950, un informe de la cia llegó a la conclusión de que las reformas de Arévalo eran "marcadamente nacionalistas" pero no comunistas, por lo que el Departamento de Estado decidió, en mayo de 1951, que "no se podía decir que el gobierno guatemalteco

\footnotetext{
${ }^{36}$ Gleijeses, Sbattered, 1991, p. 26.

${ }^{37}$ Ibid.

${ }^{38}$ Leonard, United, 1984, p. 81.
}

fuera comunista o estuviera controlado por los comunistas". 39

Sin embargo, esta posición de ninguna manera reflejaba un consenso dentro de un gobierno estadunidense que, hacia finales de 1947 , había hecho del anticomunismo el "principio organizador básico". ${ }^{40}$ Un gran número de funcionarios del Departamento de Estado, incluyendo al subsecretario, Spruille Braden, y a muchos otros funcionarios recién reclutados, veían a Arévalo como un agente del comunismo internacional. Después de haberse desacreditado por su posición de mano dura mientras tuvo el cargo de embajador estadunidense en Buenos Aires, al comienzo de la era peronista, Braden alegó que el presidente guatemalteco había prometido secretamente a los comunistas una participación en su gobierno. Incluso llegó al extremo de calificar a Arévalo de ser un agente de Stalin. Ya desde 1947, funcionarios estadunidenses de segundo rango habían afirmado que 200 comunistas, trabajando conjuntamente con Moscú, se habían infiltrado en los círculos gubernamentales y sindicalistas. ${ }^{41}$ Para 1948 , esta posición se había reafirmado en la embajada. El nuevo embajador, Richard Patterson, que había ocupado el mismo cargo en la Yugoslavia de Tito, apenas conocía Guatemala pero se preocupaba intensamente de la amenaza comunista. Patterson afirmó constantemente a los guatemaltecos que la influencia comunista crecía con rapidez

\footnotetext{
${ }^{39}$ Leonard, "Nationalism", 1990, pp. 178, 180.

${ }^{40}$ Coatsworth, Central, 1994, p. 56.

${ }^{41}$ Leonard, Central, 1989, pp. 132-133.
} 
en un país en el que no había más de 4000 comunistas, pero donde sólo 40 de ellos podían "pensar y organizarse", según el líder del partido comunista, José Fortuny. ${ }^{42}$

Como en los años veinte, estas opiniones reflejaban aquellas de los centroamericanos conservadores, quienes sabían jugar la carta anticomunista a la perfección y la usaban para manipular a los jóvenes y relativamente ingenuos empleados de las embajadas estadunidenses, para así lograr sus propios fines. Preocupada por el creciente activismo obrero y consciente de que las acusaciones de comunismo fueran escuchadas con interés en la embajada de Estados Unidos, la elite guatemalteca alimentó la paranoia de Patterson y sus asociados. Incluso el dictador nicaragüense, Anastasio Somoza García, invocó la cuestión comunista para congraciarse con Estados Unidos. Ya que Arévalo y el presidente costarricense, José Figueres, apoyaban a la Legión Caribeña (una fuerza antisomocista compuesta de exiliados de Nicaragua y la República Dominicana) no le faltaban razones al dictador nicaragüense para oponerse al gobierno guatemalteco. Consecuentemente, en alguna ocasión Somoza se quejó con un funcionario estadunidense acerca de la posición de su país, que se encontraba entre dos países "izquierdistas" como Guatemala y Costa Rica. ${ }^{43} \mathrm{~A}$ menudo descrito como un secuaz servil de Estados Unidos, Somoza explotó astuta-

${ }^{42}$ Gleijeses, Shattered, 1991, p. 195.

${ }^{43}$ Clark, United, 1992, p. 182. Para el papel de Figueres véase Longley, Sparrow, 1996, cap. 9. mente la amistad con Estados Unidos para incrementar su propia estatura política. En 1952 propuso lo siguiente: "Denme las armas y yo limpiaré Guatemala a fondo en un dos por tres". ${ }^{44}$

Debido a ello, cuando el nuevo presidente de Guatemala, Jacobo Arbenz, asumió el cargo en 1951, se enfrentó con un intensificado temor estadunidense hacia el comunismo. En el punto culminante de la guerra fría, la mera sospecha de una influencia comunista era suficiente para poner al Departamento de Estado en alerta roja. Las acciones de Arbenz difícilmente podrían haber sido calificadas de radicales; su revolución fue pro occidental y su decisión de legalizar el partido comunista y permitir manifestaciones izquierdistas lo puso en la misma banca que las sociedades democráticas aliadas con Estados Unidos. Incluso la acción más controvertida de Arbenz (la Ley de Reforma Agraria), se parecía más al cardenismo que al estalinismo: en 1952, su régimen expropió las tierras sin cultivar pertenecientes a la United Fruit Company (UFCO) y a otras compañías bananeras de Estados Unidos. ${ }^{45}$ La respuesta no se hizo esperar: un nuevo coro de voces se escuchó desde Boston y Nueva Orleans. Con su Ley de Reforma Agraria, Arbenz había antagonizado a una poderosa empresa que ejercía una gran influencia en el Departamento de Estado. El hermano del secretario de Estado, Allen Dulles, había sido nada menos que un miembro de la junta directiva de la UFCO, por lo que aprovechó la oportunidad para inundar a otras

\footnotetext{
${ }^{44}$ Matthews, World, 1971, p. 226.
}

45 Immerman, CIA, 1982, p. 65. 
secretarías y dependencias gubernamentales con informes alarmistas acerca de la "Guatemala roja". No sorprende, pues, que John Dulles haya adoptado la posición de que Arbenz deseaba convertir a Guatemala en una dictadura comunista. También alegó que agentes soviéticos se habían infiltrado en el gobierno guatemalteco. ${ }^{46}$

Hacia fines de 1952, cuando el macartismo se encontraba en pleno apogeo y Dwight D. Eisenhower ganó las elecciones presidenciales, este punto de vista sobre la revolución guatemalteca se convirtió en la política exterior oficial de Estados Unidos. Eisenhower practicó una política exterior anticomunista bastante agresiva en Latinoamérica durante su primer cuatrienio. Ya fuera con el propósito de defender los intereses económicos de su país o de frustrar las acciones que su gobierno percibía como actos de subversión soviética, su primer secretario de Estado, John Foster Dulles, actuó de manera decisiva en contra de una serie de gobiernos tercermundistas interesados en implantar reformas sociales en sus países. ${ }^{47}$ La cruzada global de Dulles por enlazar todo movimiento de liberación nacional y reforma social con la subversión soviética tuvo sus acciones más sobresalientes en el derrocamiento de los gobiernos de Mossadegh en Irán y de Arbenz en Guatemala.

Como resultado de estos cambios, Estados Unidos hizo caso omiso de las protestas de Arbenz acerca de que su gobierno no apoyaba el comunismo. El Departamento de Estado de Estados

${ }^{46}$ Rabe, Eisenbower, 1988, p. 59.
${ }^{47}$ Ibid.
Unidos le pidió al gobierno guatemalteco nada menos que prohibiera de inmediato cualquier actividad comunista, para demostrar así su lealtad hacia Estados Unidos. Esas condiciones ataban las manos de Arbenz, ya que, por un lado, no podía abandonar sus ideales democráticos $\mathrm{y}$, por otro, no podía arriesgarse a provocar la ira del gobierno estadunidense. Confiado en que Estados Unidos no iba a interferir en los asuntos internos de su país en una era en la que un sistema de tratados interamericanos protegía la soberanía de cada nación del continente, eligió la segunda opción. Según su manera de ver, tanto las reformas como la apertura política seguían siendo las mejores alternativas para confrontar al comunismo. Sin embargo, el embajador estadunidense, John Peurifoy, no compartía esta opinión. "Si el presidente no es un comunista" dijo, "de todas maneras será suficiente hasta que uno se presente". 48

En el curso de su cruzada anticomunista, era poco probable que México le prestara apoyo a la Guatemala revolucionaria. Durante los cuarenta, el gobierno mexicano había resuelto las disputas pendientes con su vecino del norte y no había mostrado ningún interés en comenzar nuevos conflictos basados en cuestiones centroamericanas. El presidente Ávila Camacho había cooperado con los Aliados durante la segunda guerra mundial, ${ }^{49}$ y decidió

${ }^{48}$ Peurifoy a Department of State, 17 de diciembre de 1953, FRUS, 1952-1954, pp. 1091. 1093.

${ }^{49}$ En un paso sin precedente, México acordó a una serie de esquemas defensivas mutuas 
resolver de inmediato las cuestiones pendientes, tales como las compensaciones a las compañías petrolíferas expropiadas. Sus sucesores, Miguel Alemán Valdés y Adolfo Ruiz Cortines, habían proseguido por el mismo camino al eliminar paulatinamente las trabas que dificultaban la inversión extranjera en México. En parte como resultado de esta política, la expansión económica de los cuarenta sacó a México de su estancamiento económico. Convencidos de que las garantías para el capital extranjero estaban aseguradas con Auvila Camacho, los inversionistas estadunidenses, provistos de grandes capitales gracias al auge económico causado por la segunda guerra mundial, canalizaron nuevamente sus capitales hacia México. Esta nueva ola de inversiones introdujo una era de cooperación entre los dos países, misma que superó el programa porfiriano de una amistad limitada con Estados Unidos. En esta encrucijada, una política similar a la de Calles en los veinte posiblemente habria puesto en peligro los lazos económicos tan beneficiosos para el país.

Este acercamiento hacia Estados Unidos estuvo acompañado por un cambio de dirección hacia la derecha dentro del gobierno mexicano -un cambio que se debió tanto a una dinámica cambiada dentro del seno del partido gobernante como a una relación económica más íntima hacia Estados Unidos. Ávila Camacho y Alemán eliminaron la influencia del ala izquierdista del PRI, dirigida por Francisco Múgica. Ellos

para la protección de Baja California y la costa del Pacífico. Torres, Historia, 1979, pp. 113121. también retardaron el proceso de redistribución de tierras y decidieron no seguir con la política del nacionalismo económico. ${ }^{50}$ Para 1952, la facción en pro del desarrollo dentro de la misma elite gobernante guió los destinos del Estado mexicano - una facción que recordaba a los científicos porfirianos. ${ }^{51}$ Esta facción seguía el antiguo lema de "orden y progreso" hecho posible por la astuta manipulación de los movimientos populares, comenzada por los cardenistas durante los últimos días de su gobierno. El "orden" se podía lograr por medio del arbitraje gubernamental entre los numerosos grupos de interés dentro de la sociedad mexicana y la supresión de los pequeños pero ruidosos grupos de oposición socialistas y comunistas. Entonces el anticomunismo se volvió la política oficial por seguir, especialmente al declarar Alemán que el comunismo era incompatible con el "mexicanismo". ${ }^{52}$ El "progreso" atraía a las masas y facciones gracias a un ambicioso programa de sustitución de importaciones, que fue ayudado por la expansión económica que tuvo lugar durante la segunda guerra mundial. ${ }^{53}$ Era obvio, pues, que dentro de este plan no habría cabida para los movimientos sociales de izquierda en Latinoamérica, excepto en lo que respecta a que podría usarse como una especie de soborno para la desilusionada izquierda mexicana. Sin embar-

\footnotetext{
539.

${ }^{50}$ Segovia, "Nacionalismo", 1968, pp. 356-

${ }^{51}$ Niblo, War, 1995.

${ }^{52}$ Medina, Historia, 1979, pp. 176-180.

${ }^{53}$ Para el programa de sustitución de importaciones, véase Vernon, Dilemma, 1963.
} 
go, incluso aquel móvil en pro de una participación activa en la política exterior se desvaneció poco a poco al encargarse el crecimiento económico de una oposición izquierdista relativamente débil.

Así, al asumir Washington el liderazgo sobre las instituciones panamericanas que había creado, y al concentrar México la atención en su propio desarrollo económico, no sorprende que le haya ofrecido escaso apoyo al gobierno de Arévalo y ninguno al de Arbenz. La ayuda dada al régimen de Arévalo se limitó a algunos gestos cordiales y a un contrato para venderle pertrechos de guerra a pequeña escala, ${ }^{54}$ aunque el ex presidente Cárdenas, que se consideraba el paladín de la izquierda desalojada del gobierno mexicano, alabó la labor de Arévalo como "un ejemplo para los pueblos oprimidos" y reafirmó su apoyo a Arévalo en "estos tiempos de la agresión armada de los grandes intereses opuestos al progreso". 55 Mientras que Ávila Camacho había simpatizado con los esfuerzos de Arévalo por lograr una democracia política, sus sucesores conservadores, Alemán y Ruiz Cortines, no aprobaron las reformas más extensas de Arbenz, que se parecían demasiado a las de la época cardenista, De hecho, Arbenz les recordaba un pasado apreciable y no tan remoto, en el cual muchas de las promesas hechas durante la revolución fue-

\footnotetext{
${ }^{54}$ Best, "Mexican", 1988, p. 168.

55 Cárdenas a Arévalo, Pátzcuaro, Michoacán, 20 de octubre de 1945, y Morelia, Michoacán, 6 de abril de 1949, en Archivo General de la Nación (en adelante AGN), Archivo Personal Lázaro Cárdenas, caja 5, exp. 2.
}

ron tomadas con mayor seriedad que durante las presidencias de Ávila Camacho, Alemán y Ruiz Cortines.

El temor de Ruiz Cortines hacia el comunismo difería fundamentalmente del de Dulles y de Eisenhower. Mientras que el gobierno estadunidense buscaba la conformidad ideológica y el servilismo económico en una nación asociada durante el apogeo de la guerra fría, el gobierno mexicano prefería amordazar a sus radicales domésticos, quienes demandaban un retorno a los "principios de la Revolución Mexicana". Esos radicales incluyeron no sólo a comunistas verdaderos como el ex líder sindical Vicente Lombardo Toledano y el muralista David Alfaro Siqueiros, sino también al ex presidente Cárdenas, que seguía siendo el paladín de la izquierda. A Ruiz Cortines, el apelativo de comunista le sirvió para desacreditar a la izquierda en México, más que en el exterior. Por ello, el gobierno mexicano no habría ayudado al gobierno de Arbenz aun si Estados Unidos no hubiese intervenido, ya que Arbenz fungía como un símbolo de aquella facción política mexicana que se oponía a la política conservadora, en pro del desarrollo de Ruiz Cortines.

Mientras que el apoyo al régimen de Arbenz quedaba descartado, eso no significaba que no habría apoyo para el abstracto principio de la autodeterminación nacional. El gobierno de Ruiz Cortines necesitaba una oportunidad para sostener este principio, que creaba un equilibrio entre los nacionalistas que se oponian al intervencionismo estadunidense y a los que apoyaban el desarrollo pero que no deseaban romper los lazos con el vecino del norte. 
En marzo de 1954 , el sistema interamericano dio al gobierno mexicano la oportunidad que precisamente estaba esperando. En vez de proceder unilateralmente en contra de Guatemala, Dulles intentó ganarse el apoyo latinoamericano para luchar en contra de la influencia "comunista" en las Américas. Para lograr su objetivo, Dulles presentó una resolución durante la X Conferencia Interamericana, que tuvo lugar en Caracas en marzo de 1954. En ella invocó un sistema de defensa interamericano para luchar en contra de la subversión comunista. ${ }^{56}$ Ya que era obvio que este fallo era un ataque disimulado en contra del gobierno de Arbenz, muchos latinoamericanos lamentaron la adopción de tal propuesta, que significaba dar a Estados Unidos mano libre para organizar una intervención.

Ya que la resolución fue percibida como una táctica especialmente insidiosa para promover el furioso anticomunismo del Departamento de Estado, forzó al gobierno de Ruiz Cortines para dar a conocer su posición públicamente y de inmediato. De cualquier manera, la delegación mexicana tendría problemas. Si aprobaba la resolución, mancharía la imagen del nacionalismo revolucionario creada por el propio gobierno mexicano. Por otro lado, si México se oponía a esta medida de Estados Unidos, abría sus puertas a acusaciones de favorecer la causa del comunismo en el continente, y se arriesgaría a provocar la hostilidad de Estados Unidos por una cuestión de poca importancia. La opinión pública mexicana

${ }^{56}$ Leonard, Central, 1989, p. 139. estaba dividida al respecto, pero el riesgo de perder el apoyo de los poderosos sectores anticomunistas ciertamente pesaba más que la posibilidad de desilusionar a la izquierda. ${ }^{57}$

Intentando complacer a ambas facciones, Ruiz Cortines le dio instrucciones a la delegación mexicana para que hiciera valer los tradicionales principios de la no intervención y la autodeterminación de los pueblos. En la conferencia, el delegado mexicano, Roberto Córdoba, discutió apasionadamente en contra de la resolución y presentó varias enmiendas que afirmaron el derecho inalienable de cada país de poder escoger su propio gobierno e instituciones. Al fracasar en su intento de influenciar a las otras naciones latinoamericanas (ni qué decir de cambiar la opinión de Estados Unidos), Córdoba tenía por lo menos la esperanza de obtener algún beneficio propagandístico de la cuestión. ${ }^{58} \mathrm{Al}$ fin y al cabo debió enfrentar la dura realidad de la guerra fría y no votó en contra de la resolución. La mayoría dirigida por Estados Unidos neutralizó todas las enmiendas que intentaron debilitar la medida, y la asamblea votó, abrumadoramente, en pro de la resolución. Sólo México, Costa Rica y Argentina se abstuvieron, y Guatemala fue el único país que votó en contra. La única victoria significativa de aquellas delegaciones latinoamericanas que se preocupaban por la intervención estadunidense fue el hecho de que la resolución se pareció más a una declaración general de política exterior que a una declaración que le permitía a

\footnotetext{
57 Best, "Mexican", 1988, p. 174.

${ }^{58}$ Pellicer, Historia, 1978, pp. 101-102.
} 


\section{SECUENCIA}

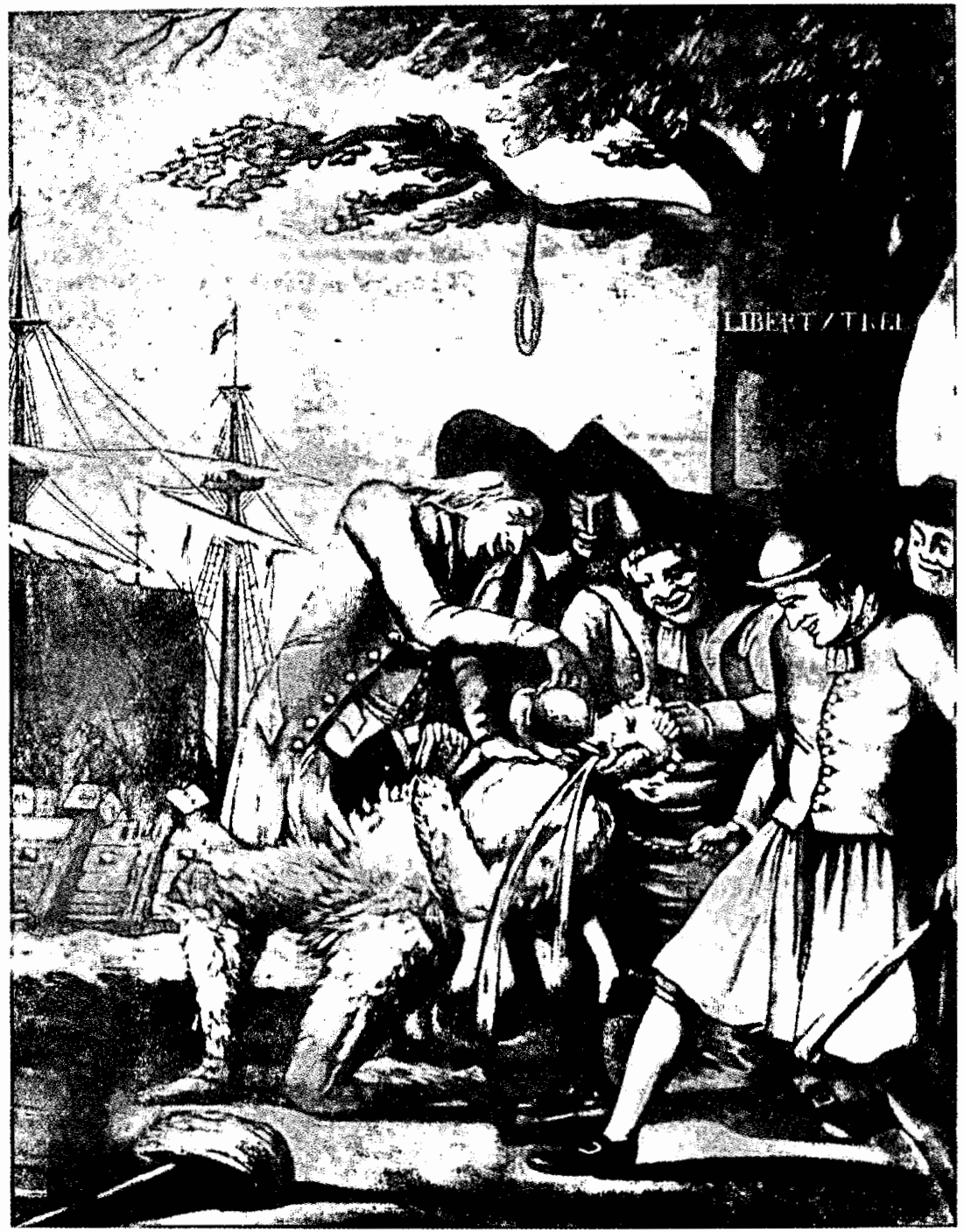


uno de los Estados miembros de la OEA interferir directamente en los asuntos internos de otro. ${ }^{59}$

La abstención de Córdoba en Caracas reveló lo difícil que se había vuel. to la política exterior de México durante la guerra fría. En México, dentro y fuera del gobierno, muchos no estuvieron de acuerdo con la postura cautelosa de Ruiz Cortines. Un gran número de mexicanos -incluyendo a los líderes sindicales, intelectuales, y los representantes de los campesinos- demandaron una posición firme en contra de lo que ellos consideraban una inminente intervención. Por ejemplo, cuando se empezó a presionar a Arbenz, Cárdenas envió un cable al ministro de Relaciones Fxteriores de Guatemala expresándole su "amistad y simpatía" hacia un país que veía "su soberanía amenazada" ${ }^{60}$ Incluso el viejo carrancista, Isidro Fabela, dio a conocer su desagrado por la falta de acción por parte del gobierno mexicano, en un artículo titulado "La conferencia de Caracas y la actitud anticomunista de México". Escondiendo cuidadosamente su crítica hacia la presidencia de Ruiz Cortines con palabras de alabanza, Fabela criticó la abstención como un "acto de mera cortesía" hacia Estados, Unidos, diciendo que era una "manera diplomática de no decir no". ${ }^{61}$ Por el otro lado, muchos grupos conservadores en México se opusieron a todo tipo de maniobras que ayudarían a lo que ellos veían co-

\footnotetext{
${ }^{59}$ Gleijeses, Shattered, 1991, pp. 277, 274 275

${ }^{60}$ Pellicer, Historia, 1978, p. 104.

${ }^{61}$ Fabela, "Conferencia", 1954, p. 16.
}

mo una "infiltración comunista" en el hemisferio. ${ }^{62}$

Escasos meses después del final de la conferencia de Caracas, el gobierno estadunidense puso término a todas las discusiones. Un envío de armas checas a Guatemala le sirvió como pretexto al gobierno estadunidense para derrocar al régimen de Arbenz. El 17 de junio de 1954, la invasión patrocinada por la CIA y dirigida por el coronel Carlos Castillo Armas usó a miles de mercenarios para acabar con los "Diez Años de Primavera" en Guatemala. Poco después, el mismo Castillo Armas se convirtió en presidente, y la UFCO obtuvo nuevamente sus propiedades perdidas con la reforma agraria. ${ }^{63}$

Aunque su delegación se expresó de la manera más poética en Caracas, Ruiz Cortines decidió abandonar los principios adoptados allí. Aun cuando Cárdenas se ofreció para mediar entre Estados Unidos y Guatemala, para impedir este acto de agresión, ${ }^{64}$ el presidente se rehusó a participar. ${ }^{65}$ Es más, después de la victoria de Castillo Armas, ni Ruiz Cortines ni ningún alto funcionario de su gobierno hicieron jamás aclaración alguna sobre el acontecimiento. Salvo una excepción, ni siquiera las organizaciones populares asociadas con el gobierno protestaron en contra de tan flagrante acto de intervencionismo estadunidense. Impedidas por una mordaza oficial proveniente

${ }^{62}$ Best, "Mexican", 1988, p. 174

${ }^{63}$ Immerman, $C L A, 1982$, pp. 133-186.

${ }^{64}$ Cárdenas a Ruiz Cortines, Apatzingán, Michoacán, 21 de junio de 1954, en ANG, Archivo Personal Lázaro Cárdenas, caja 5, exp. 2.

65 Best, "Mexican", 1988, p. 175. 
de Ruiz Cortines, misma que incluía una prohibición de manifestaciones para apoyar a Arbenz, muchos de sus líderes se resignaron a censurar la invasión en privado. ${ }^{66}$

En pleno apogeo de la guerra fría, las autoridades mexicanas permitieron una cruzada anticomunista organizada por Estados Unidos, mas aún así sostuvieron la tradición de apoyar el derecho de autodeterminación de las naciones. La negativa del gobierno de comentar acerca del golpe de Estado que derrocó a Arbenz reflejó un reconocimiento de la realidad geopolítica de ser el vecino inmediato de uno de los protagonistas más poderosos del conflicto este-oeste. Sin embargo, al restringir las actividades antiintervencionistas y las manifestaciones de apoyo a Arbenz, México se guió más por una lógica interna que externa, misma que reveló el clima político conservador imperante en el país. México se había convertido en el aliado de Estados Unidos, y la amenaza del comunismo, ya sea real o imaginaria, era un enemigo público para ambos países. Al final, sólo la necesidad de demostrarle al mundo cierto grado de independencia de la política exterior estadunidense había prevenido que se aprobara la campaña anticomunista de Estados Unidos en forma de un voto de aprobación durante la conferencia de Caracas.

\section{MÉXICO Y LA REVOLUCIÓN CUBANA, 1959-1964}

Si bien Arbenz había encontrado poca simpatía en su lucha de sobrevivencia

\footnotetext{
${ }^{66}$ Pellicer, Historia, 1978, pp. 102-103.
}

contra el anticomunismo yanqui, la insurrección cubana de Fidel Castro fue otra cosa. La intervención estadunidense en la guerra de Independencia, en 1898, comprometió la soberanía de la isla. Desde la ocupación militar, al comienzo del siglo, la presencia de Estados Unidos se había inmiscuido en todos los aspectos de la política interna de Cuba. La Enmienda Platt, de 1901, dio al gobierno estadunidense el derecho de intervenir en el caso de cualquier disturbio interno; los empresarios estadunidenses determinaron cómo y en dónde se construirían las nuevas carreteras y puertos; y, en el caso del presidente Ramón Grau San Martín, en 1933, la influencia de Estados Unidos llegó al grado de derrocar a un líder que Washington menospreciaba. También implicaba una íntima relación social y cultural, ya que los turistas financiaban el juego y la prostitución en La Habana. ${ }^{67}$ Para cuando Fulgencio Batista se convirtió en dictador, en 1952, el poder político y económico se había vuelto sinónimo de la influencia estadunidense. Mientras que la clase media cubana siguiera estando satisfecha con su gobierno y los precios del azúcar se mantuvieran altos, en una economía basada totalmente en el endulzante, los críticos de tal in. fluencia se quedaron callados. Sin embargo, al avanzar la década de los cincuenta, una crisis económica y la existencia de una dictadura sostenida por Estados Unidos produjo una oposición a la tutela estadunidense. Al acabar con las reformas de los gobiernos anteriores, Batista usó el espectro de la guerra

${ }^{67}$ Perez, Cuba, 1997, pp. 152-201 
fría para sus propios fines, convirtiéndose no sólo en el amo incontestable de Cuba sino también en un títere de Estados Unidos. Mientras tanto, los precios del azúcar en los mercados mundiales sufrieron una caída estrepitosa, afectando la economía cubana. ${ }^{68}$ Fueron estos vínculos tan estrechos entre Estados Unidos y Cuba aquellos que el movimiento castrense del 26 de julio deseaba enfrentar, y los mexicanos entendieron bien este reto. El impulso nacionalista de la revolución cubana tuvo el beneplácito de muchos mexicanos, quienes comparaban los eventos en Cuba con lo que había ocurrido en México en 1910. Por ejemplo, el embajador de México en La Habana, Gilberto Bosques, apoyó la destitución de Batista. ${ }^{69}$

El presidente Adolfo López Mateos, que fue el gobernante mexicano más progresista desde Cárdenas, se encontraba entre aquellos que inicialmente habían apoyado la revolución castrista. A diferencia de sus dos predecesores, quienes habían alcanzado cierta notoriedad por su alianza con los intereses empresariales, López Mateos se alineó con las organizaciones trabajadoras y campesinas, y prometió un retorno al populismo cardenista. Ayudado por más de una década de expansión económica sostenida, e inspirado por el ejemplo de otros populistas sudamericanos como los Perón de Argentina y Juscelino Kubitschek de Brasil, se de. dicó a cumplir las promesas no realizadas de la revolución. Específicamente, repartió poco más de 12000000 de

${ }^{6}$ Pérez-Stable, Cuban, 1999.

${ }^{69}$ Villasana, "Evolución", 1994, p. 13. hectáreas a los campesinos sin tierras, en el reparto agrario más grande desde los días de Cárdenas. Sin embargo, por debajo de su postura populista, López Mateos conocía bien las reglas del juego que mantenían al PRI en el poder. Como cualquier otro presidente posrevolucionario, necesitaba rendirle homenaje a la revolución mientras tranquilizaba a los inversionistas respecto a la orientación capitalista del sistema político mexicano. $^{70}$

Como en el caso guatemalteco, la política exterior de Estados Unidos no permitió un verdadero acercamiento entre Cuba y México. Como ya hemos visto, desde el punto de vista de Estados Unidos, el conflicto entre dicho país y la Unión Soviética dividió al mundo en los capitalistas buenos y los comunistas malos. Hacia comienzos de los sesenta, tras una fase inicial, durante la cual los responsables de formular la política exterior estadunidense dudaban qué dirección tomaría la revolución cubana, la confiscación de las propiedades extranjeras puso a Castro, sin lugar a dudas, en la órbita comunista. Por lo tanto, cualquier simpatía mexicana demasiado evidente hacia la revolución cubana pondría en peligro la relación que el país tenía con Estados Unidos.

De hecho, la primera reacción mexicana hacia el triunfo de Castro fue ambivalente. La victoria de los rebeldes el 1 de enero de 1959 pasó casi inadvertida para la prensa mexicana, debido a que los incidentes fronterizos con Guatemala eclipsaron los eventos

\footnotetext{
${ }^{70}$ Pellicer, Historia, 1978.
} 
cubanos. ${ }^{71}$ Además, los principales periódicos estuvieron divididos en sus reacciones ante los sucesos en Cuba. Mientras que los artículos en Novedades y en Tiempo celebraban la victoria de Castro como un hito más en el largo camino de Latinoamérica hacia la liberación nacional, Aldo Baroni, el editor de Excélsior lamentó la caída de Batista, a quien describió como el responsable de haber dado a Cuba un periodo de estabilidad, y pintó al grupo de Castro como una pandilla de aventureros. Mientras tanto, el gobierno mexicano aplaudió el gran acontecimiento. El 5 de enero la Secretaría de Relaciones Exteriores anunció el reconocimiento del nuevo presidente cubano, Manuel Urrutia Lleó. ${ }^{72}$

Al correr del tiempo, la "imagen romántica de la revolución de Castro comenzó a capturar la imaginación del público mexicano". El secretario de Relaciones, José Gorostiza, favoreció el cambio de gobierno en Cuba. Además, en febrero de 1959, doce rebeldes que habían sido compañeros en la Sierra Maestra visitaron México, y el grupo fue recibido con gran entusiasmo. Conforme pasaba el año, el programa revolucionario ganaba cada vez más adeptos en México. Como señaló el embajador Gilberto Bosques, las primeras acciones de Castro, que incluían la reforma agraria y la nacionalización de la propiedad extranjera, tenían cierta semejanza con las iniciativas que había

\footnotetext{
${ }^{71}$ Wolff, "Mexican-Guatemalan", 1981, pp. 235-248.

${ }^{72}$ Novedades, 6 de enero de 1959; Tiempo, 12 de enero de 1959; Excélsior, 2 de enero de 1959.
}

tomado el presidente Cárdenas en los treinta. No sorprendía, pues, que el mismo Cárdenas emergiera como el "paladín de Castro" durante esos años, y el carismático ex presidente organizó a los izquierdistas mexicanos para que apoyaran la revolución cubana. ${ }^{73}$

Los revolucionarios cubanos repetían las primeras reacciones mexicanas hacia su movimiento, ya que Castro había pasado gran parte de su exilio en México, por lo que no fue ninguna coincidencia que comenzara su levantamiento en ese país. Además, recordó que el gobierno mexicano le había permitido organizar su rebelión contra Batista sin obstáculo alguno. Sabía bien que esta permisividad hacia su grupo contrastaba con la Doctrina Estrada, que otorgó el reconocimiento de México a cualquier gobierno establecido, un reconocimiento que implicaba que el territorio mexicano no se usaría en contra de tal gobierno -lección que, durante su estadía en Yucatán, había tenido que aprender el patriota nicaragüense José C. Sandino. Después de la victoria, Castro se refirió en repetidas ocasiones a la revolución mexicana como una guía en la lucha contra el régimen de Batista. Lo que no reveló fue que la expe. riencia mexicana lo había convencido de que tendría que conducir su revolución de manera muy distinta, para así poder evitar el destino común de Madero, Carranza y Obregón, todos ellos asesinados por la oposición. Por ello, Castro consolidó su poder rápidamente y sin escrúpulos. ${ }^{74} \mathrm{El}$ aprendizaje

\footnotetext{
${ }^{73}$ Smith, "Mexico", 1970, pp. 46, 52; Villasana, "Evolución", 1994, pp. 18-19.

${ }_{74}$ Pellicer, México, 1972, pp. 13, 90-97.
} 
político de su asesor, el Che Guevara, tuvo lugar en Guatemala, en 1954, donde el entonces médico argentino fue testigo de los últimos días del gobierno de Arbenz. Después del golpe de Estado patrocinado por Estados Unidos, Guevara viajó a la ciudad de México con un salvoconducto. Ya ahí, lamentó la falta de movilización y organización de la revolución guatemalteca democrática, que no pudo impedir la mezcla de la oposición conservadora, con la United Fruit Company y la agresión de Estados Unidos. ${ }^{75}$ Debido a la falta de documentos, solamente se puede suponer que también censuraba que México no hubiera intervenido para salvar al régimen de Arbenz.

López Mateos se percató en seguida del poderío que la revolución cubana ejercía en México. Él sabía que el triunfo de Castro bien podía recordarles a los mexicanos que el PRI se había apropiado y también había asfixiado del ímpetu de la revolución mexicana y también lo había asfixiado. Un aliado del ex líder laboral Vicente Lombardo Toledano, de inmediato se aprovechó de esta oportunidad, y fomentó una huelga ferrocarrilera en marzo de 1959 , la que fue rápidamente aplastada por las fuerzas de seguridad pública mexicanas. Sin embargo, este despliegue de fuerza le demostró a López Mateos lo bien organizada que estaba la izquierda, tanto afuera como adentro del PRI. Lo que era aún más preocupante para el gobierno mexicano era que el ex presidente Cárdenas comenzó a criticar en forma abierta las decisiones del

${ }^{75}$ Rojo, Friend, 1968, pp. 53-59. presidente, una violación de la confidencialidad y lealtad de la familia revolucionaria mexicana que no tenía precedentes. ${ }^{76}$ Finalmente, Siqueiros se unió también a la riña, declarando en un periódico que el movimiento de Castro había dejado muy atrás a la Revolución Mexicana. ${ }^{77}$

Por lo tanto, el presidente comenzó un acto de malabarismo en el cual la Cuba de Castro jugó un papel crucial. Por un lado, defendió la revolución cubana contra el gobierno de Estados Unidos y contra los conservadores dentro de su propio país. En junio de 1960, López Mateos demostró su apoyo recibiendo al presidente cubano Osvaldo Dorticós. Durante la visita, el mandatario de México declaró:

\begin{abstract}
Nosotros que hemos recorrido etapas semejantes, comprendemos y valoramos el esfuerzo de transformación que Cuba está llevando a cabo. También aquí la reforma agraria ha sido factor determinante de la patria nueva de que estamos orgullosos. Confiamos en que la Revolución Cubana sea, como lo ha sido la nuestra, un paso más hacia la grandeza de América. ${ }^{78}$
\end{abstract}

Por otro lado, el uso de la mano dura para suprimir cualquier disturbio laboral puso de manifiesto que estaba decidido a mantener el orden público en México. A pesar de que en alguna ocasión haya declarado que se encontraba a "la izquierda dentro de la Constitución", López Mateos estaba determinado a aplastar a aquellos que, a su

\footnotetext{
${ }^{76}$ Smith, "Mexico", 1970, pp. 46-57.

77 Tiempo, 1 de febrero de 1960.

${ }^{78}$ Pellicer, México, 1972, pp. 19-21.
} 
modo de ver, se encontraban a la izquierda de la Constitución. ${ }^{79}$ Este segundo elemento de su estrategia resultó ser crucial para su sobrevivencia política, ya que su declaración, hecha durante la visita de Dorticós, había enajenado a los conservadores. ${ }^{80}$

Sin embargo, la radicalización de la revolución cubana y la hostilidad de Estados Unidos socavaron su estrategia. Durante 1960, Estados Unidos y Cuba chocaron sobre el derecho de Castro de confiscar propiedades extranjeras y redistribuir tierras agrícolas, por lo que Castro se movía paulatinamente hacia la izquierda. La visita del vicepremier soviético, Anastas Mikoyan, en febrero, y el acuerdo resultante de comprarle el petróleo a la Unión Soviética, constituyeron las primeras señales de que Castro se convertiría en un aliado del archienemigo estadunidense si Estados Unidos se oponía a su revolución. En junio, Castro nacionalizó las refinerías pertenecientes a compañías estadunidenses, por su rechazo a procesar el crudo soviético, y en julio el gobierno de Estados Unidos cortó la cuota azucarera cubana como represalia (por cierto, una acción que benefició a los exportadores azucareros mexicanos). Un mes más tarde, Castro se desquitó confiscando aún más compañías estadunidenses, y en diciembre declaró que su revolución era de índole socialista, precediendo al rompimiento estadunidense de relaciones diplomáticas con Cuba. Estos sucesos dieron al gobierno de Estados Unidos el pretexto que buscaba para organizar

${ }^{79}$ Meyer, Course, 1999 , p. 652.

${ }^{80}$ Política, 1 de junio de 1960 , pp. 6-7. una invasión. Ya desde abril de 1960, el presidente Dwight D. Eisenhower había autorizado el equipamiento de una expedición para derrocar a Castro. Un año más tarde, las tropas de exiliados cubanos entrenados por la ClA desembarcaron en Playa Girón, al sur de Ia Habana. A pesar de que el ejército de Castro venció rápidamente a los invasores, este incidente fue el más sobresaliente de los esfuerzos sostenidos de Estados Unidos para derrocar a gobiernos "comunistas" en el hemisferio. ${ }^{81}$

La invasión de Playa Girón, aunque ignorada oficialmente por el gobierno mexicano, ilustró el dilema eterno de la política exterior nacional hacia $\mathrm{Cu}$ ba. Mientras que la hostilidad de Estados Unidos impedía acciones mexicanas de apoyo abierto hacia Castro, López Mateos necesitaba responder a las presiones políticas de índole doméstica y, además, el presidente se encontraba con el problema de aplacar a dos grupos que habían adoptado dos programas de acción diametralmente opuestos. Por un lado, los izquierdistas y nacionalistas inútilmente le demandaron a López Mateos que apoyara y defendiera a Castro, y una vez más, Cárdenas encabezó los esfuerzos para lograrlo e incluso consideró ir a Cuba para ayudar a Castro en su lucha contra la intervención extranjera. ${ }^{82}$ Por otro lado, los conservadores y los inversionistas extranjeros le urgían al gobierno mexicano unirse a Estados Unidos para condenar al régimen de Castro. ${ }^{83}$ Los dos grupos sólo tenían una cosa

\footnotetext{
${ }^{81}$ Pérez, Cuba, 1997, pp. 241-252.

82 Ojeda, Alcances, 1976 , pp. $82-83$

${ }^{83}$ Pellicer, México, 1972, p. 29.
} 
en común: el rechazo a una intervención militar de Estados Unidos en Latinoamérica.

Por lo tanto, López Mateos practicó rápidamente un nuevo acto de malabarismo, ignorando al régimen de Castro pero a la vez defendiendo el derecho cubano de la autodeterminación dentro del sistema interamericano. Este acto de malabarismo satisfizo tanto a los mexicanos izquierdistas como a los nacionalistas y conservadores, y no danó sustancialmente las relaciones de México con Estados Unidos. Además, esta política estaba de acuerdo con las ideas nacionalistas pero anticomunistas del propio presidente. Con esta política, López Mateos no hizo sino continuar con la tradición diplomática mexicana comenzada bajo Díaz, de invocar las experiencias amargas que tuvo México con las potencias extranjeras como un argumento para contrarrestar la intervención estadunidense en el Caribe y en Centroamérica.

Al percatarse de que la revolución cubana se había radicalizado, con la consecuente alianza cubano-soviética, el presidente mexicano dejó de enfatizar las similitudes existentes entre la experiencia histórica de México y $\mathrm{Cu}$ ba. Se había vuelto demasiado obvio que Castro había decidido no seguir el experimento mexicano de una reforma gradual. Como se mencionó anteriormente, las apresuradas expropiaciones y sus despiadados actos represivos pusieron de manifiesto que el líder cubano había decidido eliminar toda oportunidad que pudieran tener sus oponentes de influenciar la política revolucionaria. Todavía no sabemos hasta qué punto el análisis que Castro hizo de la revolución mexicana haya influenciado su propio compromiso de proseguir con una reforma radical en Cuba, pero desde el punto de vista de la elite anticomunista mexicana, Castro aspiraba a convertirse en un dictador marxista que había adoptado una doctrina extraña a Latinoamérica, en vez de proseguir por el camino indicado y luchar por tierra y libertad como sucedió con la revolución mexicana. En enero de 1962, el secretario de Relaciones Exteriores, Manuel Tello-quien estaba mucho menos dispuesto al cambio revolucionario en Cuba que su antecesor- declaró que el marxismo-leninismo era incompatible con la membresía en la Organización de Estados Americanos. ${ }^{84}$

Sin embargo, López Mateos se mantuvo firme en su rechazo a la intervención extranjera en Cuba. Más adelante, en 1962, cuando Estados Unidos y la mayoría de los Estados latinoamericanos votaron para expulsar a Cuba de la OEA, el gobierno mexicano se rehusó a romper relaciones diplomáticas con dicho país. ${ }^{85} \mathrm{La}$ crisis de los misiles de Cuba, en octubre de 1962, es otro caso pertinente. Después de consultar el asunto con el presidente John F. Kennedy, el mandatario mexicano no titubeó en unirse a la OEA en su condena a Castro por solicitar los misiles soviéticos. Sin embargo, añadió un requisito importante a su apoyo de la moción, al declarar que la posición de México no implicaba que accediera a una invasión estadunidense de Cuba.

${ }^{84}$ Ibid., pp. 29-30.

${ }^{85}$ Ojeda, Alcances, 1976 , p. 46; Padilla, "Presence", 1969. 
Dos años más tarde, el gobierno mexicano hizo caso omiso de una resolución de la OEA que pretendía cortar todos los lazos diplomáticos y viajeros con Cuba. ${ }^{86}$

A pesar de esta retórica nacionalista, para esta época que coincide con el inicio de la gestión del presidente estadunidense Lyndon B. Johnson, ya existía un acuerdo amplio entre México y Estados Unidos de que se debía combatir la subversión comunista. ${ }^{87}$ No sorprende, pues, que si la negativa a suspender el servicio aéreo a La Habana daba la impresión de ser un desafío hacia Estados Unidos, la cuestión de los viajes entre México y la Cuba rev. olucionaria demostró una vez más la ambivalencia de la posición mexicana. No cabe duda de que los vuelos de Mexicana de Aviación -junto con otros pocos vuelos de otras aerolíneas que todavía seguían volando de Europa a La Habana- constituyeron la ventana de Cuba al mundo. Los pasajeros estadunidenses evitaron el embargo de su gobierno volando a la ciudad de México y cambiando de vuelo allí para proseguir a Cuba, y por su parte los cubanos viajaban primero a México para dirigirse de allí al resto del mundo occidental. Sin embargo, el gobierno estadunidense obtuvo una importante concesión de su contraparte mexicana a cambio de tolerar la continuación del servicio aéreo. Los funcionarios mexicanos pusieron a disposición de la Embajada de Estados Unidos en México listas detalladas de todos los pasa-

\footnotetext{
${ }^{86}$ Pellicer, México, 1972, pp. 35-36.

${ }^{87}$ Suárez, "México", 1986, pp. 71-128.
}

jeros que tomaban estos vuelos. Como resultado de ello, tanto los inmigrantes como los turistas extranjeros ponían en peligro su futuro ingreso a Estados Unidos -una expectativa que ha disuadido a muchos visitantes extranjeros, incluyendo al autor, de viajar a Cuba desde México. ${ }^{88}$

Buscando demostrar el sincero compromiso que ha tenido para efectuar un cambio social y político en Latinoamérica, el gobierno mexicano inicialmente recibió con beneplácito a la revolución cubana. Después de que la injerencia de Estados Unidos y la posterior radicalización de la revolución erosionaron el apoyo inicial dado a Castro, la defensa del derecho cubano de autodeterminación encajaba muy bien con la tradición diplomática nacionalista de México. Al defender la independencia cubana, más que la política de Castro, López Mateos le enseñó a México y al mundo que su gobierno siempre estaría dispuesto a defender el derecho de cada nación a hacer sus propias leyes. Al recordar las luchas pasadas que tuvo su país en contra de la intervención extranjera, su política encontró el apoyo tanto de los conservadores como de los progresistas. El gobierno estadunidense, interesado en la estabilidad política de su vecino del sur, dio a México "una dispensación especial para diferir en cuestiones de política exterior"; ${ }^{89}$ una dispensación con la que ni Calles ni Ruiz Cortines habían contado en su política.

\footnotetext{
${ }^{88}$ Riding, Distant, 1984, p. 343.

${ }^{89}$ Ojeda, Alcances, 1976, p. 93.
} 


\section{CONCLUSIONES}

Cuando Ronald Reagan declaró la guerra al gobierno sandinista de Nicaragua al asumir la presidencia, en 1981, la retórica anticomunista ya tenía una larga tradición. Concebida como una manera de detener el nacionalismo económico de México y la inestabilidad política de Nicaragua, esta retórica quedó firmemente implantada en las mentes de los arquitectos de la política exterior estadunidense durante la guerra fría. En los ochenta, el anticomunismo de Estados Unidos se había convertido en una doctrina, a tal grado que Reagan, quien había ayudado a impulsar un renacimiento de muchos de los valores y las actitudes imperantes durante el apogeo de la guerra fría, finalmente terminó su presidencia con algo de amar. gura, porque su cruzada en contra de los movimientos centroamericanos para crear más justicia social lo llevó a desacatar al Congreso de su país. Al hacerlo, la definición de un comunista siguió siendo la esencia de los comentarios sarcásticos de Josephus Daniels, el embajador de Estados Unidos durante la era cardenista, quien en alguna ocasión dijo que "un comunista es cualquier maldito tipo que no nos agrada".

A pesar de que México fue la primera víctima de las cruzadas anticomunistas que se discutieron en este trabajo de investigación, y en las otras dos fue un inocente espectador, no es posible entender su respuesta a la política exterior estadunidense en términos de su contexto geopolítico. En cambio, los episodios analizados aquí revelan la importancia del contexto doméstico -posrevolucionario en el primer caso, en pro del desarrollo en el segundo, y reformista en el tercero- en la formulación de la política exterior mexicana. Es obvio que ningún gobierno mexicano ha formulado su diplomacia en un vacío, mientras que la presencia de Estados Unidos y de otros factores internacionales demarcan y determinan su radio de acción. Pero, a fin de cuentas, el firme anticomunismo del gobierno mexicano (y sus concomitantes temores de estimular movimientos izquierdistas en el país) explica la actitud algo fría que tomó hacia los esfuerzos estadunidenses de derrocar a Arbenz y a Castro. En vista de estas realidades, no sorprende el hecho de que una cruzada anticomunista (que en alguna ocasión amenazó al mismo México) no haya engendrado apoyo para otras naciones latinoamericanas. Dejando a un lado las dificultades inherentes de encontrar y evaluar la documentación existente en los archivos acerca de cómo toma forma la política exterior mexicana, la nueva historia diplomática debe aceptar por ello el contexto doméstico de la diplomacia mexicana. Por otro lado, la vieja historia diplomática mexicana que describe las relaciones internacionales como un incesante estira y afloja entre las naciones no basta para poder explicar la compleja y a menudo contradictoria política exterior mexicana.

\section{ARCHIVOS}

AGN Archivo General de la Nación, México.

AHSREM Archivo Histórico de la Secretaría de Relaciones Exteriores, México.

NAW National Archives Washington. 


\section{HEMEROGRAFÍA}

-El Universal, Ciudad de México. -Excélsior, Ciudad de México. -Excélsior, Guatemala. -New York Times, Nueva York. -Novedades, Ciudad de México. -Política, Ciudad de México. -The Boston Herald, Boston. -Tiempo, Ciudad de México.

\section{BIBLIOGRAFÍA}

-Aguilar Zinser, Adolfo, "Mexico and the guatemalan crisis" en Richard R. Fagen, The future of Central America: policy choices for the United States and Mexico, Stanford University Press, Stanford, California, 1983.

-Arnson, Cynthia J., Crossroads: congress, the president and Central America, 1976-1993, Pennsylvania State University Press, University Park, Pensilvania, 1995.

-Bagley, Bruce M., "Mexican foreign policy: the decline of a regional power?", Current History, vol. 82, diciembre de 1983, pp. 406-409 y 437.

, "Mexico in Central America: the limits of regional power" en Wolf Grabendorff y otros, Political change in Central America: internal and external dimensions, Westview Press, Boulder, Colorado, 1984.

-Beals, Carleton, "Mexico seeking Central American leadership", Current History, vol. 24 , núm. 6 , septiembre de 1926 , pp. 839-844.

-Best, Edward H., "Mexican foreign policy and Central America since the Mexican Revolution," tesis de doctorado, Oxford University, 1988.

-Buchenau, Jürgen, In the shadow of the giant: the making of Mexico's Central America policy, 1876-1930, University of Alabama Press, Tuscaloosa, 1996.
México y el movimiento liberal en Nicaragua, Fideicomiso Archivos Plutarco Elías Calles y Fernando Torreblanca, Boletín núm. 9, México.

-Carter, Calvin B., "The Kentucky feud in Nicaragua: why civil war has become her national sport", The World's Work, vol. 54, núm. 3, julio de 1927, pp. 312-321.

-Clark, Paul Coe, The United States and Somoza, 1933-1956: a revisionist look, Praeger, Westport, Connecticut, 1992.

-Coatsworth, John H., Central America and The United States: the clients and be colossus, Twayne Publishers, Nueva York, 1994.

-Coolidge, Calvin, Conditions in Nicaragua: message from the president of the United States transmitting to the Congress of the United States the conditions and the action of the government in the present disturbances in Nicaragua, Government Printing Office, Washington, 1927.

-Dosal, Paul, Doing business with the dictators: a political bistory of United Fruit in Guatemala, 1899-1944, Scholarly Resources, Wilmington, Delaware, 1993.

-Fabela, Isidro, "La conferencia de Caracas y la actitud anticomunista de México", Cuadernos Americanos, vol. 75, núm. 3, mayo-junio de 1954, pp. 1-33.

-Gleijeses, Piero, Shattered bope: the guatemalan revolution and the United States, Princeton University Press, Princeton, 1991.

-Grabendorff, Wolf, "The role of regional powers in Central America: Mexico, Venezuela, Cuba and Colombia", en Heraldo Muñoz, Latin American nations in world politics, Westview Press, Boulder, Colorado, 1984.

-Harrison, Benjamin T., Dollar diplomat: Chandler Anderson and american diplomacy in Mexico and Nicaragua, 1913-1928, Washington State University Press, Pullman, 1988.

-Herrera Zúñiga, René y Mario Ojeda, "La política de México en la región de 
Centroamérica", Foro Internacional, vol. 23, núm. 4, abril de 1983, pp. 423-440.

-Horn, James J., "Did the United States plan an invasion of Mexico in 1927?", Journal of Inter-American Studies and World Affairs, vol. 15, núm. 4, noviembre de 1973, pp. 454-471.

- "El embajador Sheffield contra el presidente Calles", Historia Mexicana, vol. 20, núm. 2, octubre de 1970, pp. 265-284.

, "U.S. diplomacy and the specter of 'bolshevism' in Mexico (1924. 1927)", The Americas, vol. 32, núm. 1, julio de 1975, pp. 31-45.

-Hunt, Michael H., Ideology and U.S. foreign policy, Yale University Press, New Haven, Connecticut, 1987.

-Immerman, Richard H., The CIA in Guatemala: the foreign policy of intervention, University of Texas Press, Austin, 1982.

-Kamman, William, A searcb for stabili. ty: U.S. diplomacy toward Nicaragua, 1925-1933, University of Notre Dame Press, South Bend, Indiana, 1968.

-Knight, Alan, The mexican revolution, Cambridge University Press, Cambridge, 1986, 2 vols.

-Krenn, Michael L., U.S. Policy toward economic nationalism in Latin America, 1917-1929, Scholarly Resources, Wilmington, Delaware, 1990.

-LaFeber, Walter, Inevitable revolutions: The United States in Central America, Princeton University Press, 2a ed., Princeton, Nueva Jersey, 1993.

-Langley Lester D. y Thomas D. Schoonover, The banana men: american mercenaries and entrepreneurs in Central America, 1880-1930, The University Press of Kentucky, Lexington, 1995.

-Leffler, Melvyn P., The specter of communism: The United States and the origins of the cold war, 1917-1953, Hill \& Wang, Nueva York, 1994.

-Leonard, Thomas, Central America and the United States: the search for stability, University of Georgia Press, Athens, 1989. nism? The truman administration and Guatemala, 1945-1952", Journal of Third World Studies, vol. 8, primavera de 1990, pp. 34-51. The United States and Central America, 1944-1949: perceptions of political dynamics, University of Alabama Press, Tuscaloosa, 1984.

-Longley, Kyle, The sparrow and the bawk: The United States and Costa Rica, 1944-48, University of Alabama Press, Tuscaloosa, 1996.

-Matthews, Herbert, A world in revolution, Scribners, Nueva York, 1971.

-Medina, Luis, Historia de la revolución mexicana, 1940-1952: civilismo $y$ modernización del autoritarismo, El Colegio de México, México, 1979.

-Meyer, Jean y otros, Historia de la revolución mexicana, 1924-1928: Estado y sociedad con Calles, El Colegio de México, México, 1977.

-Meyer, Lorenzo, Mexico and the United States in the oil controversy, 1917. 1942, University of Texas Press, Austin, 1972.

-Meyer, Michael C. y otros, The course of mexican bistory, Oxford University Press, 7a. ed., Oxford, 1999.

-Niblo, Steven, War, diplomacy and development: the United States and Mexico, 1938-1954, Scholarly Resources, Wilmington, Delaware, 1995.

-Ojeda, Mario, Alcances y limites de la política exterior de México, El Colegio de México, México, 1976.

- "Mexican policy toward Central America in the context of U.S.-Mexico relations" en Richard R. Fagen, The future of Central America: policy choices for the United States and Mexico, Stanford University Press, Stanford, California, 1983.

(comp.), Las relaciones de México con los paises de América Central, El Colegio de México, México, 1985.

-Padilla Nervo, Luis, "The presence of Mexico at the United Nations: the cuban 
case" en Carlos A. Astiz, Latin american international politics: ambitions, capabilities, and the national interest of Mexico, Brazil and Argentina, University of Notre Dame Press, Notre Dame, Indiana, 1969.

-Pellicer de Brody, Olga, "Mexico in Central America: the difficult exercise of regional power" en Richard R. Fagen, The future of Central America: policy. choices for the United States and Mexico, Stanford University Press, Stanford, California, 1983. - México y la revolución cu. bana, El Colegio de México, México, 1972.

- y Esteban L. Mancilla, Historia de la revolución mexicana, 1952-1960: el entendimiento con Estados Unidos y la gestación del desarrollo estabilizador, El Colegio de México, México, 1978.

-Perez, Louis A. Cuba and the United States: ties of singular intimacy, University of Georgia Press, 2a. ed., Athens, 1997.

-Pérez-Stable, Marifeli, The cuban revolution: origins, course and legacy, Oxford University Press, 2a. ed., Oxford, 1999.

-Rabe, Stephen G., Eisenbower and Latin America: the foreign policy of anticommunism, University of North Carolina Press, Chapel Hill, 1988.

-Riding, Alan, Distant neigbbors: a portrait of the mexicans, Knopf, Nueva York, 1984.

-Rojo, Ricardo, My friend Che, Nueva York, 1968.

-Salisbury, Richard V., Anti-imperialism and international competition in Central America, 1920-1929, Scholarly Resources, Wilmington, Delaware, 1989.
-Segovia, Rafael, "El nacionalismo mexicano: los programas políticos revolucionarios, 1929-1964", Foro Internacional, vol. 8, núm. 4, abril de 1968, pp. 349-359.

-Selser, Gregorio, El pequeño ejército loco: operación México-Nicaragua, Bruguera, 2a. ed., México, 1980.

-Smith, Arthur K., "Mexico and the cuban revolution: foreign policy-making in Mexico under president Adolfo Lópe\% Mateos (1958-1964)," tesis doctoral, Cornell University, 1970.

-Spenser, Daniela, El triángulo imposible: México, Rusia soviética y Estados Unidos durante los años veinte, Porrúa, México, 1998.

-Suárez Argüello, Ana Rosa, "México, los Estados Unidos y el anticomunismo (19631969)", Nuestra América, vol. 16, eneroabril de 1986, pp. 71-127.

-Torres Ramírez, Blanca, Historia de la revolución mexicana, 1940-1952: México en la segunda guerra mundial, El Colegio de México, México, 1979.

-Vernon, Raymond, The dilemma of Mexico's development: the roles of the private and publics Sectors, Harvard University Press, Cambridge, 1963.

-Villasana Cardoza, Luz María, "La evolución de la política exterior de México hacia Cuba a partir de 1959", tesis de licenciatura, Universidad Iberoamericana, México, 1994.

-Wolff, Thomas, "Mexican-Guatemalan imbroglio: fishery rights and national honor", The Americas, vol. 38, núm. 2, octubre de 1981, pp. 235-248. 


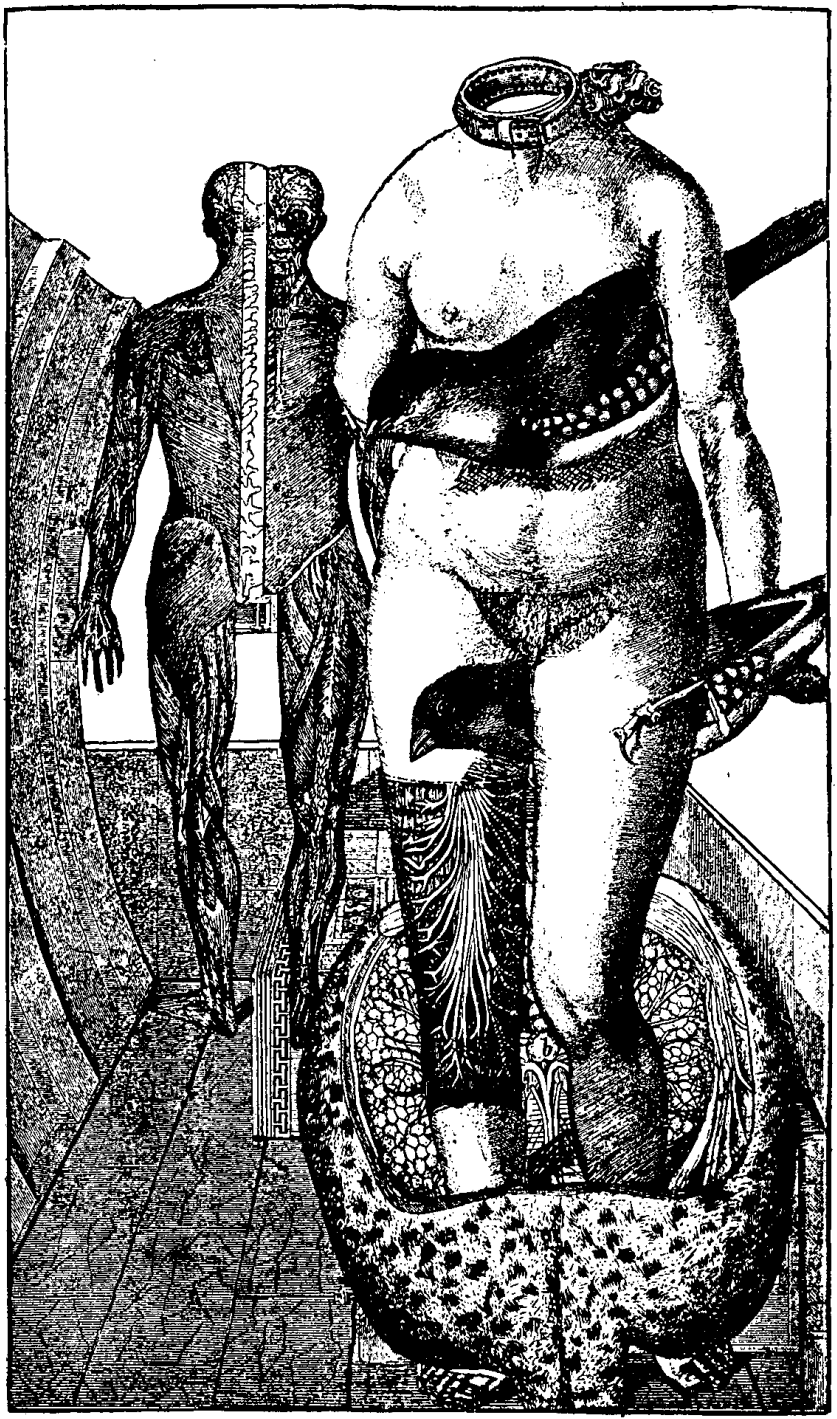

